\title{
Exploring Advocacy Self-efficacy Among K-12 STEM Teacher Leaders
}

\author{
Richard Carlos L. Velasco ${ }^{1}$ (D) Rebecca Hite $^{2} \cdot$ Jeff Milbourne $^{3}$ \\ Received: 14 September 2020 / Accepted: 17 March 2021 / Published online: 3 April 2021 \\ (C) The Author(s) 2021
}

\begin{abstract}
Advocacy is an emergent dimension of teacher leadership, given its growing importance in shaping policy and facilitating reform efforts in American K-12 education. In 2014, the National Academies called for advancing advocacy-based activities and leadership among K-12 science, technology, engineering, and mathematics (STEM) teachers, who are presently understudied. The purpose of this embedded single-case case study was to explore STEM teachers' development of self-efficacy in advocacy for STEM education. Contextualizing the case, participants consisted of 11 STEM teacher leaders who were part of the STEM Teacher Ambassadors (STA) program, a year-long advocacy-focused leadership development fellowship program, jointly sponsored by the National Science Teaching Association and National Council of Teachers of Mathematics. Employing case study research methodology, primary data were collected using semi-structured interviews, while secondary data were sourced via focus group interview and documents to triangulate interview data. Utterances (i.e., participant statements, groups of statements, or segments of statements) from transcribed data were coded a priori and analyzed via four constructs of self-efficacy theory: enactive master experiences, vicarious experiences, verbal persuasion, and emotional arousal. Results revealed 157 utterances coded to self-efficacy building within STEM education advocacy. Findings suggest that STEM teacher leaders' participation in professional development programs that specifically focus on development of policy knowledge and advocacy activities help to develop and sustain STEM teacher leaders' advocacy selfefficacy, given that participating teachers have numerous opportunities to fully engage in mastery experiences in STEM education advocacy. Implications and recommendations for policy and suggestions for further studies are discussed.
\end{abstract}

Keywords Advocacy · Self-efficacy · Case study · STEM · Teacher leadership

Richard Carlos L. Velasco

richard-velasco@uiowa.edu

Extended author information available on the last page of the article 


\section{Introduction}

Recent initiatives in K-12 science, technology, engineering, and mathematics (STEM) education have strived to strengthen the STEM teacher workforce in America by advancing teacher leadership (Honey, Pearson, \& Schweingruber, 2014; National Education Association, 2019; U.S. Department of Education, n.d.; Wynne, 2001). The development and improvement of STEM teacher leaders suggests an increase in student success in STEM (Elrod \& Kezar, 2017) and improvement in STEM education curricula (Barcelona, 2014). As a result, there have been a growing number of studies on the topic focusing on development of STEM teacher leadership in the policy space (Blömeke \& Klein, 2013; Criswell et al., 2018; National Research Council [NRC], 2014; Kokka, 2018; Yow, Wilkerson, \& Gay, 2020) to meet these outcomes.

\section{Defining STEM Teacher Leadership and Advocacy}

Given that definitions of teacher leadership vary among the extant literature (Wenner \& Campbell, 2017), different studies navigate various foci of teacher leadership. For instance, studies in the teacher leadership literature span topics on leadership development and activities at the classroom, district, or local levels, augment the significance of curriculum leadership, or discuss advancement to administrative positions through distributed leadership (e.g., Alemdar, Cappelli, Criswell, \& Rushton, 2018; Muijs \& Harris, 2003; Nguyen \& Hunter, 2018). Because of the variation in definitions of teacher leadership, Wenner and Campbell (2017) have sought to define teacher leadership, in each and every study, to bridge this need and gap within the literature. Thus, the present study adopted the following definition of teacher leadership from YorkBarr and Duke (2004): "the process by which teachers, individually or collectively, influence their colleagues, principals, and other members of the school community to improve teaching and learning practices with the aim of increased student learning and achievement" (pp. 287-288). Given that an understanding of educational policy is a specific operation of teacher leadership (Teacher Leadership Exploratory Consortium [TLEC], 2012), advocacy is vital in achieving this aim. Gen and Wright (2013) defined advocacy as "intentional activities initiated by the public to affect the policy making process" (p. 165), with a goal in making change to current policy. Thus, synthesizing these definitions of teacher leadership and advocacy, the present study conceptualizes STEM teacher advocacy as teacher leadership as intentional activities by STEM teacher leaders to influence STEM education policy.

However, the current literature is lacking in scholarship regarding STEM teacher advocacy, particularly taking into account teacher leadership at larger scales, such as STEM teacher leaders' abilities to advocate for STEM education reform and capacities or otherwise influence STEM education policy at state, regional, or national scales (Hite \& Milbourne, 2018; Velasco, 2020). Understanding teacher leadership beyond the classroom is particularly important for STEM teachers, as they represent content areas that are in the current zeitgeist as socially conscious and politically charged (Chung, Yoo, Kim, Lee, \& Zeidler, 2016; Vakil \& Ayers, 2019). Furthermore, the involvement and contribution of STEM teacher leaders in the policy-making sphere have benefits for the STEM ecosystem: sharing STEM education expertise with policymakers, influencing and enforcing school policies and practices in STEM, and making decisions that impact student success in STEM areas (Merrill \& 
Daugherty, 2010). Yet, there is an absence of STEM teacher voices in the creation and establishment of STEM education policies (Pennington, 2013; Sunderman, Tracey, Kim, \& Orfield, 2004), which has been cited as one of many reasons teachers are leaving the profession (Carver-Thomas \& Darling-Hammond, 2017). Remarkably, "teacher policy advocates are among the least studied stakeholders in U.S. publication education reform today" (Jones, Khalil, \& Dixon, 2017, p. 445). These factors warrant examination of how STEM teacher leaders become advocates beyond the classroom by engaging in advocacy activities. Understanding the nature of this developmental process in advocacy can help to build pipelines for exemplary STEM teachers to engage in STEM education reform.

\section{Self-efficacy Theory}

One theory that may contribute to understanding this process and potentially model how teachers decide which actions to take in leadership such as advocacy is self-efficacy (Leithwood \& Jantzi, 2008), or an individual's belief in their capability of successfully executing a given task (Bandura, 1977). Furthermore, Bandura asserted that self-efficacy is situational, meaning that having high self-efficacy in one context (e.g., STEM teaching) may not necessarily translate to having high self-efficacy in another context (e.g., STEM education advocacy). As such, studies have indicated that teaching self-efficacy correlates to several outcomes in teacher performance (e.g., Caprara, Barbaranelli, Steca, \& Malone, 2006; Perera, Calkins, \& Part, 2019), which appropriates the need to explore self-efficacy in the context of a specific practice, like advocacy. Hence, the four constructs of self-efficacy theory can be adapted to analyze influential sources of advocacy self-efficacy among STEM teacher leaders: (1) enactive master experiences, which refer to un/successful (advocacy) experiences that inform self-efficacy; (2) vicarious experiences, which refer to observations of successes or failures of models (other STEM advocates); (3) verbal persuasion, which refers to positive or negative feedback from either an external (colleagues) or internal (self) source; and (4) emotional arousal, which refers to human emotions such as anxiety and fear as well as health-related issues. Together, these four sources uniquely contribute to selfefficacy, modeling human behavior in regard to the goals that individuals set, estimating the amount of effort they are willing to expend toward said goals, and to what degree they are willing to continue toward their goals when faced with obstacles or challenges (Bandura, 1997). A study by Hofstein, Carmi, \& Ben-Zvi (2003) found that sustained leadership development for chemistry teachers not only improved their personal beliefs as a leader, but also their professional beliefs and abilities in teaching, suggesting that high-quality professional development (PD) can positively augment teachers' self-efficacy in teaching and leadership. Likewise, the purpose of this study was to explore sources of self-efficacy (enactive master experiences, vicarious experiences, verbal persuasion, emotional arousal) and how such sources may have an impact on self-efficacy development among STEM teacher leaders in advocacy. The present study was guided by the following research question: To what extent do the sources of self-efficacy influence advocacy self-efficacy of STEM teacher leaders?

\section{STEM Teacher Ambassadors Program}

Given the importance of developing STEM education advocates, robust PD programs are recruiting groups of extant STEM teacher leaders (those who have evidenced 
teacher leadership as defined above and have been vetted by the community of practice as such) to provide them with the knowledge and skills to engage in these efforts (Yow et al., 2020). One such group in STEM education is the STEM Teacher Ambassadors (STA), a National Science Foundation (NSF)-supported program jointly administered by the National Science Teaching Association (NSTA), and the National Council of Teachers of Mathematics (NCTM). Strict selection criteria ensured participant vetting as each applicant must have previously received the Presidential Award for Excellence in Mathematics and Science Teaching (PAEMST; Weiss, Smith, \& O'Kelley, 2009), which recognizes exemplary science and math teachers honored by the White House's Office of Science and Technology Policy. By ensuring that participants are vetted instructional leaders in science or mathematics K-12 teaching, programmatic experiences may leverage that extant leadership and build upon it, for leadership in advocacy within their content areas. To that end, two small cohorts (10 members per cohort) of these nationally recognized science and mathematics teachers engaged in a year-long fellowship, during which they were provided policy information and trained in advocacy skills so they could effectively engage in STEM education advocacy at the local, state, and federal levels (Falk \& Finkel, 2018).

\section{Conceptual Framework: Situating Self-efficacy in STEM Teacher Advocacy}

A conceptual framework (Fig. 1) of the present study theorizes how STEM teachers develop self-efficacy in STEM education advocacy. The assumption of this model suggests that STEM teachers with high self-efficacy (such as the aforementioned STAs) are an ideal population of study since they may be more inclined to participate in PD to learn and enact policy-based (advocacy) activities for STEM education. Thus, examining their experiences in these advocacy activities, through the lens of self-

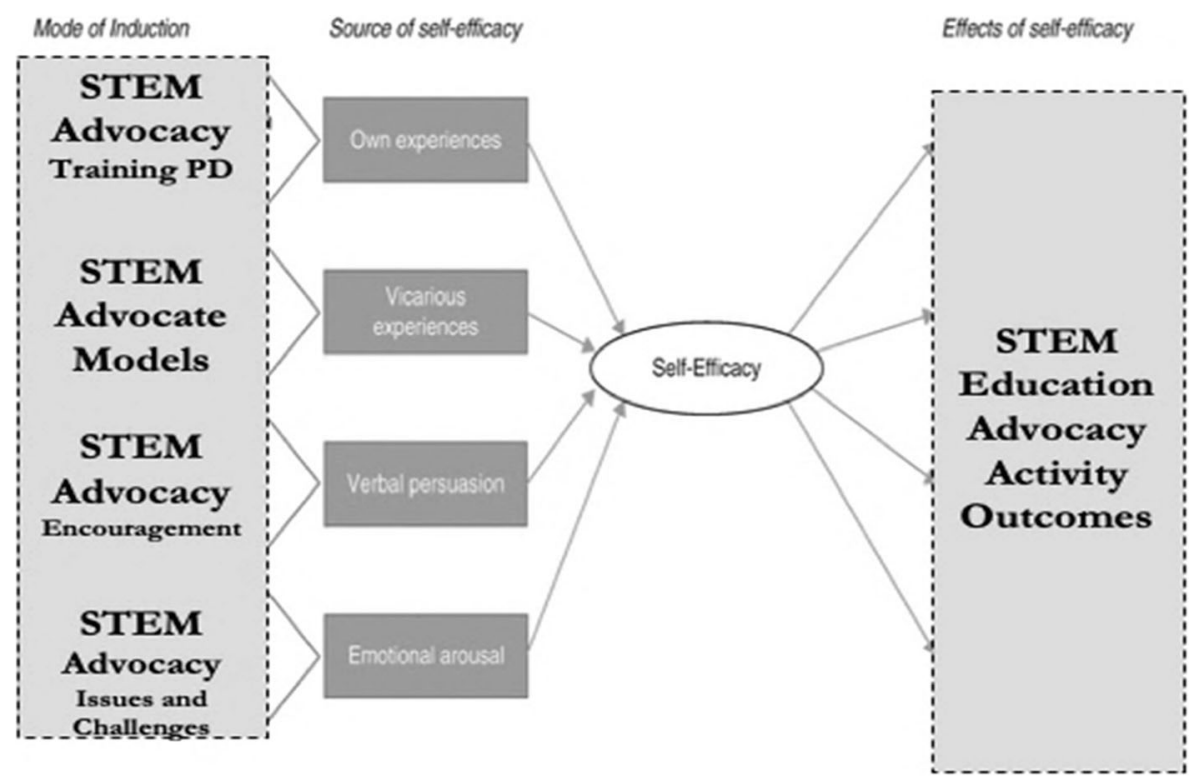

Fig. 1 Conceptual framework modeling advocacy-based self-efficacy 
efficacy constructs, may illuminate situated factors (sources) that contribute to a STEM teacher's self-efficacy in advocacy. In other words, the constructs of self-efficacy in enactive master experiences, vicarious experiences, verbal persuasion, and emotional arousal all theoretically influence STEM teacher leaders' self-efficacy in STEM education advocacy. This logic has concurrent validity with the decades of research in other situated forms of self-efficacy, specifically teacher self-efficacy (Berman \& McLaughlin, 1977), a highly situated adaptation (and now variant) of self-efficacy theory.

While having high self-efficacy in teaching does not equate to high self-efficacy in advocacy, situating extant (vetted) STEM teacher leaders within a specific programmatic context about policy and advocacy may foster teachers' self-efficacy in STEM education advocacy. Given the situated nature of self-efficacy, policy knowledge and advocacy skills would need to be delivered through targeted and sustained experiences, such as high-quality PD administered both in-house and outside the typical classroom setting (Morris, Chrispeels, \& Burke, 2003). Therefore, we had confidence that the STEM Teacher Ambassador program itself (i.e., mastery experiences) was only one source of the influences on participants' advocacy self-efficacy. Other sources of advocacy self-efficacy may be vicariously living through other more experienced colleagues (Lunenburg, 2011), verbal persuasions from administrators and colleagues (Blömeke \& Klein, 2013), or managing advocacy-related anxieties (i.e., emotional arousal) (Brooks \& Schweitzer, 2011), as examples. Hence, the model examines the confluence of the four self-efficacy constructs as mediating goal setting, effort, and persistence (Bandura, 1997) in advocating for K-12 STEM education. As such, keeping in line with the purpose of the present study, advocacy experiences before, during, and after participation in the STA program were also explored.

\section{Methods}

An embedded single-case case study (per Yin, 2018) was employed (Fig. 2) to evidence self-efficacy through situated teacher leadership (advocacy-based activities) within the case of a PD STA program experience to develop participants' (alumni

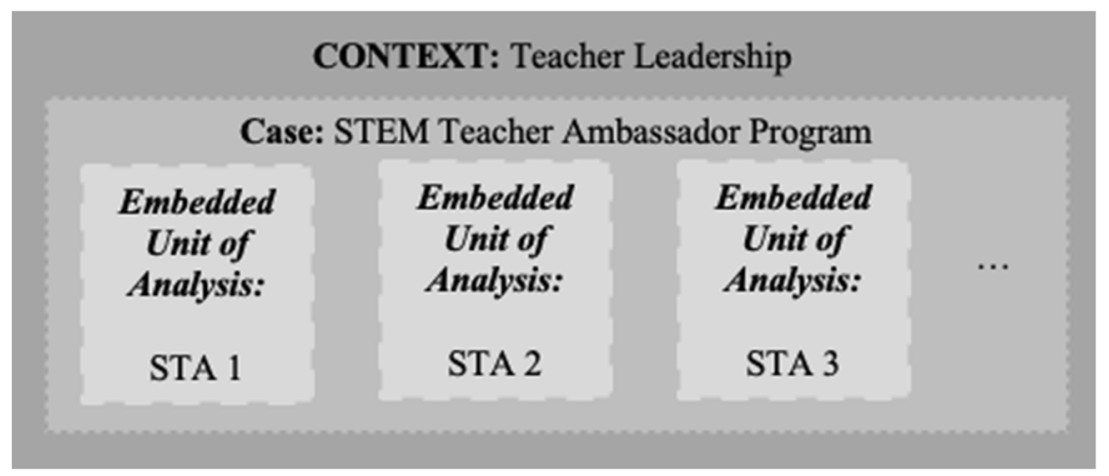

Fig. 2 Illustrative model of a single-case embedded design for the present study. Adapted from Yin (2018) case study research and applications: design and methods (6th Edition). Thousand Oaks, CA: Sage Publications, Inc. 
fellows') policy knowledge and advocacy skills. The embedded units of analysis are the individual STAs and their activities shared among fellows.

\section{Context of the Case}

While the STA program's aim was not to explicitly develop STEM teachers' advocacy selfefficacy, the present study makes the argument that recruiting specific participants (STAs) with strong self-efficacy in STEM teaching may shed light on the development of their advocacy self-efficacy. The STA program began in 2017, under NSF-funded grant 1554059 to "expand the teacher leader's knowledge of key K-12 STEM education issues and hone their interpersonal skills so that they can communicate important messages more effectively with education stakeholders" (Falk \& Finkel, 2018, para. 1). Each year of the program, ten PAEMST awardees were selected from a pool of over 120 applicants. Each STA received a week-long STEM education advocacy training in Washington D.C., meeting with advocacy experts and leaders from NSTA and NCTM to conduct media interviews and write op-eds; communicate more effectively and deliver key messages to the public; engage with local and state officials; prepare effective materials for meetings with local, state, and federal policymakers; successfully convey policy ideas to thought leaders; and use social media, specifically Twitter, to amplify messaging. Furthermore, STAs were provided with organizational and PD opportunities throughout their cohort year, from NSTA and NCTM, to bring STEM education awareness to all relevant stakeholders, including working cooperatively and collaboratively with policymakers to inform effective STEM education policy.

\section{Participants and Sampling}

The program had two cohorts of 10 STAs (20 STAs total) consisting of eight males and 12 females, each of whom received an email requesting their participation. Eleven STAs, five from the first cohort and six from the second (55\% of total STAs), responded and participated in the research study. Table 1 presents demographics of the STAs.

Table 1 Participants' demographic information: gender, teaching level, and STEM discipline

\begin{tabular}{llll}
\hline Pseudonym & Gender & Level taught & STEM discipline*** \\
\hline Mark & Male & Secondary & Math \\
Paul & Male & Secondary & Science \\
Ben & Male & Elementary & STEM \\
Dave** & Male & Secondary & Science \\
Lisa** & Female & Elementary & Science \\
Jane & Female & Elementary & Science \\
Mary** & Female & Elementary & STEM \\
Sue & Female & Secondary & Science \\
Beth** & Female & Secondary & Math \\
Anna & Female & Secondary & Science \\
Lou & Female & Secondary & Science \\
\hline
\end{tabular}

\footnotetext{
**Not currently in the classroom; held an educational leader role at the time of being an STA
}

***Disciplines identified by participant. None identified as a technology or engineering teacher 


\section{Researchers' Roles}

In this case study, the first author was an insider-researcher as he was a member of the group being studied (Breen, 2007). In addition to contributing data to the present study, being an insider-researcher had multiple advantages: (a) the researcher has a greater understanding of the culture being studied; (b) the researcher's participation did not alter the flow of social interaction unnaturally; and (c) the researcher has an established intimacy which promotes both the telling and the judging of truth (Bonner \& Tolhurst, 2002). As such, the first author was a member of the second cohort of STAs, and his participation and membership of the STA program influenced and prompted his decision to conduct the present study in particular. Unluer (2012) suggests, however, that there are also disadvantages in being an insider-researcher, such as analyzing data as an in-group member possibly leading to ethical issues of bias or not seeing the greater picture outside the group. In order to mitigate bias, a second researcher (not an STA) confirmed and validated data. Additionally, the second researchers' expertise in STEM teacher leadership in policy (Hite \& Milbourne, 2018; Velasco, 2020) provided a well-informed perspective on data analysis.

\section{Data Sources}

The gathering of multiple data sources is an inherent and integral component in a robust qualitative case study (Yin, 2018); as such, the data sources were as follows: (a) individual semi-structured interviews, which were the primary source of data as they spoke to the STA experiences in advocating for STEM education; (b) a focus group interview (secondary source) that consisted of smaller subgroups of the participants, but included members of both STA cohorts; and (c) document data (for triangulation). Individual interviews gave in-depth attention to the lived experiences of the STEM teacher leader participants (Dworkin, 2012), pointing to their work in policy-based advocacy. Furthermore, the focus group interview was conducted to draw out similarities and differences among STEM education advocacy experiences that happened between members of both STA cohorts. Finally, the collection and analysis of document data triangulated interview data and provided a more detailed view (Bowen, 2009) into the policy-based advocacy work done by sampled STAs.

Individual Semi-structured Interviews. These interviews (Appendix 1) were held over the course of 3 months, from June to August of 2019. Interviews drew out participant references of self-efficacy constructs (enactive mastery, vicarious experiences, verbal persuasions, and instances of emotional arousal) situated to their advocacy goals and actions (activities). Semi-structured interviews provided evidence of STEM education advocacy through the experiences shared by the STAs (Castillo-Montoya, 2016). Furthermore, these interviews provided participants a private venue to discuss their experiences and for the researcher to draw out details in STEM education policy-based advocacy work through unique follow-up questions (Kvale, 2006). The individual interviews were $45 \mathrm{~min}$, conducted and recorded using the video conference application Zoom. The first author was interviewed by the second author to ensure the trustworthiness of the protocol and mitigate bias in collecting data from the first author, whose responses as a former STA contributed to the data set. 
Focus Group Interview. Conducting the focus group helped determine how STAs advocated for STEM education, both individually and as a collective group. The focus group protocol (Appendix 2) was informed particularly by the vicarious experiences shared by the participants in their individual interviews. Bandura (1977) warned that social persuasion and subjective biases may form in group interviews; therefore, data gleaned from the focus group was used to help inform theory to ground teacher leadership research and provided a holistic perspective of K-12 STEM advocacy activities among sampled STAs.

To conduct the focus group, a second email was sent to the STA participants requesting their participation in a focus group interview, which was also conducted and recorded using Zoom. The focus group was one 45-min session held in October 2019. The focus group consisted of six STAs, three from the first cohort and three from the second. The first author served as the interviewer and moderator for the focus group (Taylor, 2011) and used a moderator's guide of a narrative explaining the study, introductory questions, transition questions, and ending questions (Krueger \& Casey, 2014). For both the individual and focus group interviews, the online application Otter was used to help transcribe audio data. All data were de-identified and stored in an encrypted area for analysis.

Document Data. Documentary evidence of STAs' advocacy activities was requested to provide a contextual overview, through collected artifacts, of how STAs engaged in advocacy activities (Ralph, Birks, \& Chapman, 2014). Collection of documents spanned from June to October of 2019. First, curriculum vitae (CVs) revealed publications, such as policy briefs, editorials, and articles that communicated the ways in which STEM teacher leaders exerted their influence for STEM education in their respective communities. Second, correspondences (e.g., emails to legislators) presented evidence of discourse, critical to exerting teacher voice in policy (Cohen, 2010). And last, posts from their Twitter accounts demonstrated STAs' real-time advocacy activities online (Guo \& Saxton, 2014; McPherson, Budge, \& Lemon, 2015).

\section{Analysis}

In total, 38 files from interviews, the focus group, $\mathrm{CV}$, tweets, and artifacts (i.e., articles, op-eds, policy letters, emails) were loaded into NVivo 12 (2018) for analysis (Table 2).

Utterances (statements, groups of statements, or segments of statements) taken from the transcribed individual and focus group interviews were analyzed using the twocoding cycle technique recommended by Saldaña (2015). An example of such an utterance from the data set is from Ben during his individual interview who said, "I would say, I have always been an advocate." Another example of an utterance from the focus group interview comes from Lou: "The big hurdle is the administration's view of teacher leadership and the importance of STEM." NVivo 12 organized these codes (utterances) in the first cycle into a priori categories using the four constructs of selfefficacy theory, such that data could be categorized into emergent themes (in the second cycle of coding). Table 3 shows a summary of the a priori codes for the present study, which was also used as a codebook for the research team? and inter-raters to ensure reliability across the data related to the constructs of self-efficacy. 
Table 2 Data $(N=38)$ sourced from 11 STA participants

\begin{tabular}{llllll}
\hline Pseudonym & Interview & Focus group* & $\mathrm{CV}^{* *}$ & Tweets** & Artifacts** \\
\hline Mark & $\mathrm{X}$ & $\mathrm{X}$ & $\mathrm{X}$ & $\mathrm{X}$ & $\mathrm{X}$ \\
Paul & $\mathrm{X}$ & & $\mathrm{X}$ & $\mathrm{X}$ & \\
Ben & $\mathrm{X}$ & $\mathrm{X}$ & $\mathrm{X}$ & $\mathrm{X}$ & \\
Dave & $\mathrm{X}$ & $\mathrm{X}$ & $\mathrm{X}$ & $\mathrm{X}$ & $\mathrm{X}$ \\
Lisa & $\mathrm{X}$ & $\mathrm{X}$ & $\mathrm{X}$ & & \\
Jane & $\mathrm{X}$ & & $\mathrm{X}$ & $\mathrm{X}$ & \\
Mary & $\mathrm{X}$ & $\mathrm{X}$ & $\mathrm{X}$ & $\mathrm{X}$ & $\mathrm{X}$ \\
Sue & $\mathrm{X}$ & & & $\mathrm{X}$ & \\
Beth & $\mathrm{X}$ & & $\mathrm{X}$ & $\mathrm{X}$ & \\
Anne & $\mathrm{X}$ & & $\mathrm{X}$ & $\mathrm{X}$ & \\
Lou & $\mathrm{X}$ & $\mathrm{X}$ & $\mathrm{X}$ & $\mathrm{X}$ & $\mathrm{X}$ \\
No. of sources: & 11 & 6 & 10 & 10 & 4 \\
\hline
\end{tabular}

Collection of data sources was a result of voluntary submission of requested documents

*There was one transcription document for the focus group interview

** Data sources used for triangulation

For tweets, Nvivo 12 has a feature that connects the program to the online Twitter application and has the capability of extracting data from tweets. A total of 2108 individual tweets and retweets from 10 accounts (one STA did not utilize Twitter) were captured. Filtering tweets by the word "STEM," which included variations with the pound symbol (\#) or "hashtags" (e.g., \#STEMeducation, \#STEMambassador, \#STEMteaching) narrowed the tweets pool to 1053 tweets, (50\% of the total number of extracted tweets) for analysis.

\section{Trustworthiness}

Consistent with Lincoln and Guba's (1985) recommendations, the present study took steps toward each of the four trustworthiness criteria: credibility, transferability, confirmability, and dependability. To address credibility, methods of data triangulation were utilized to check the consistency of findings by using focus group and document data as secondary sources to inform analysis of the individual interviews, which were

Table 3 Summary of codes for a priori sources of self-efficacy

\begin{tabular}{|c|c|c|c|}
\hline Enactive master experiences & Vicarious experiences & $\begin{array}{l}\text { Verbal } \\
\text { persuasion }\end{array}$ & $\begin{array}{l}\text { Emotional } \\
\text { arousal }\end{array}$ \\
\hline $\begin{array}{l}\text { "successful K-12 STEM classroom } \\
\text { teaching" }\end{array}$ & $\begin{array}{l}\text { "observing STEM teacher leader } \\
\text { models: mentors" }\end{array}$ & "encouragement" & $\begin{array}{l}\text { "stress and } \\
\text { anxiety" }\end{array}$ \\
\hline $\begin{array}{c}\text { "internal and external STEM } \\
\text { education organizations" }\end{array}$ & $\begin{array}{l}\text { "observing STEM teacher leader } \\
\text { models: STA colleagues" }\end{array}$ & “discouragement & $\begin{array}{l}\text { "health } \\
\text { issues" }\end{array}$ \\
\hline $\begin{array}{l}\text { "communication with significant } \\
\text { policy actors" }\end{array}$ & & & \\
\hline
\end{tabular}


the primary data source. Use of self-efficacy theory as a credible and vetted model (framework) has strong concurrent validity, having been applied extensively in numerous studies across many disciplines (e.g., Bliss \& Dressner, 2015; Pajares, 1996; Tschannen-Moran, Hoy, \& Hoy, 1998). For transferability, a rich description of the research setting and a detailed account of the experiences during the data collection process was recorded. For confirmability, inter-rater reliability (IRR) was conducted. The interview data, comprising 217 utterances with a mean of $20(S D=2.87)$, was first coded by the author of the study. The data were parsed (six and five interviews, respectively) and intercoded by two different researchers. Using the Miles and Huberman (1994) method of summing binary agreement, IRR was calculated by dividing the number of agreements by the total number of utterances. Interration for six interview transcripts between the original coder and first inter-coder was $78 \%, 71 \%$, $81 \%, 86 \%, 82 \%$, and $65 \%$ with an IRR percentage of $77 \%$. Interration between the original coder and a second inter-coder was $65 \%, 61 \%, 89 \%, 81 \%$, and $83 \%$, with an IRR percentage of $76 \%$. Upon inspection of the disagreements, the first coder had misinterpreted and overcoded for code 4 (emotional arousal) and the second coder took a broader conceptualization of code 5 (STEM teacher advocate identity) and overcoded utterances in this category. A third coder was employed to double code the entire data set (all 11 interviews) to settle disagreements between the original coder, first, and second inter-coders to obtain a minimum of $80 \%$ agreement (Miles \& Huberman, 1994). The third coder consulted with the original coder on the code book and expanded the coding process to allow for greater visualization of utterances; the previous coding processes only allowed for one code per utterance, and in this round, each utterance could have up to two codes per utterance. From this inter-coding, 74 additional codes were added to the original 157 codes with a mean of 6.7 codes $(S D=$ 2.19) among the 11 interviews. Binary agreement was expanded to accommodate for additional codes and partial agreement between the third coder and original coder or inter-coders one and two. This second round of interration produced the following levels of agreement (within each of the 11 interviews): $84 \%, 79 \%, 71 \%, 78 \%, 83 \%$, $78 \%, 90 \%, 82 \%, 89 \%, 96 \%$, and $83 \%$ with an overall IRR percentage of $83 \%$. The results of the second and final round of coding were reviewed by the original coder, and remaining qualitative data were coded by the original coder. Last, dependability was achieved by having an outside researcher conduct an external audit of the present study. The outside researcher who assisted in the dependability process was not a member of the research team, but is an expert in case study methodology. The researcher confirmed the present study's dependability by reading data collection and analysis procedures detailed in the original manuscript, as well as verifying final data. For transparency, pseudonyms accompanied quotations to serve as an audit trail.

\section{Results}

Table 4 summarizes the frequency of descriptive codes extracted from participants' data sources that mapped onto resulting a priori themes. Percentages and $N$ sizes are based on a total of $N=157$ a priori codes from the study. In general terms, the selfefficacy construct of enactive master experiences was the most frequent a priori theme as it had mapped $61 \%(N=96)$ of the total codes, followed by the constructs of 
Table 4 Frequency of a priori codes $(N=157)$ from primary and triangulated data sources

\begin{tabular}{lllll}
\hline Pseudonym & $\begin{array}{l}\text { Enactive master } \\
\text { experiences }\end{array}$ & $\begin{array}{l}\text { Vicarious } \\
\text { experiences }\end{array}$ & $\begin{array}{l}\text { Verbal } \\
\text { persuasion }\end{array}$ & $\begin{array}{l}\text { Emotional } \\
\text { arousal }\end{array}$ \\
\hline Mark & 3 & 1 & 3 & 0 \\
Paul & 11 & 2 & 0 & 1 \\
Ben & 12 & 6 & 4 & 2 \\
Dave & 5 & 1 & 2 & 0 \\
Lisa & 14 & 5 & 1 & 2 \\
Jane & 11 & 3 & 0 & 2 \\
Mary & 8 & 3 & 5 & 1 \\
Sue & 8 & 3 & 2 & 1 \\
Beth & 6 & 1 & 0 & 0 \\
Anne & 7 & 2 & 1 & 2 \\
Lou & 11 & 2 & 2 & 1 \\
Frequency (total \%) & $96(61 \%)$ & $29(18 \%)$ & $20(13 \%)$ & $12(8 \%)$ \\
\hline
\end{tabular}

vicarious experiences with $18 \%(N=29)$ of the total codes, and verbal persuasion with $13 \%(N=20)$ of the total codes. The construct of emotional arousal was the least frequent with $8 \%(N=12)$ but was still evident in the data. As the data were analyzed deductively using the constructs of self-efficacy as a theoretical lens, the results are further explicated per constructs of enactive master experiences, vicarious experiences, verbal persuasion, and emotional arousal.

\section{Enactive Master Experiences}

The most frequently referenced construct of self-efficacy was enactive master experiences $(N=96,61 \%)$. Throughout the interviews, STAs expressed the ways in which varied experiences of advocacy throughout their career have influenced their decision to continue to advocate for STEM education. As mentioned previously, having been awarded the PAEMST was a prerequisite in applying for the STA program. All PAEMST awardees must demonstrate effectiveness in STEM teaching through video recordings of classroom teaching. Given the nature of the award in terms of successful STEM teaching practices, STAs leveraged their teaching experiences to know what educational STEM resources and materials would be beneficial for their students, classroom, and school. As Ben explained in his individual interview:

I would say I've always been an advocate, since early on, and I started teaching in 1993. By 1995, I was already teaching workshops to other teachers on how to do hands-on, you know, hands-on science labs. In 1998, I got a...\$10,000 grant to start an after-school STEM program.

STAs also referenced presenting at various practitioner conferences hosted by national STEM education organizations. Some STAs also held leadership positions in these organizations as evidenced by their CVs, while others, such as Lisa, sought out 
opportunities to further their specific skills in STEM education advocacy. She explained in her interview that she "became the director for the preschool elementary committee. And part of that then was going on Capitol Hill, and talking to them about, you know, science and STEM. And so, then the next natural step, seemed like...[the]... STEM ambassador program.”

Speaking with key players in the STEM education policy arena enabled STAs to not only share what policies they felt needed to be set, but also become more familiar with the policy-making process. Because of this proactive involvement with learning more about STEM education policy, STAs were made more aware of the available funding for STEM education initiatives in their state, thus positively influencing them to further their advocacy by applying for these funds. As Anne stated in her individual interview:

We need money for STEM as well because obviously, you know, you can't let kids carry out, you know, a lot of these higher-level activities if you don't have the money for them. Right now, I'm trying to get a grant for some virtual goggles because I think my students would really benefit from virtual tours of the system. I teach anatomy. I think that's important to them to see it that way. And what they can do with technology is pretty amazing.

One STA, Lou, also expressed her challenges in advocating for STEM education but these difficulties did not deter her from continuing in advocacy. For the most part, much of the challenges that she faced came as resistance from those within the education system itself, as Lou expressed during the focus group interview, "I think that there is a huge hurdle if you want it. The big hurdle is the administration's view of teacher leadership and the importance of STEM." Yet Lou overcame this lack of support, as she followed up her previous statement, saying, "I've found my voice to stand up for not only myself, but for students and other teachers. I'm not scared to speak out about things as much. I'm not hesitant to do that."

As seen on their CVs, a few STAs had prior experience working with policymakers of STEM education, but most indicated that they had no knowledge or experience working with policy at the federal or state level prior to the program. For example, in reference to promoting coding and having engineering practices embedded in the K-12 curriculum in his state, Dave mentioned:

I didn't know [the policies] for our district. Oh, gosh. I mean, that's what we're pushing for, for our state to have policy to [embed coding and engineering practices into curriculum]. But the state's very resistant on doing K-12 policy in that regard.

Similarly, Lisa articulated that before participating in the STA program, she was unfamiliar with the STEM education policy space and what it meant to be an advocate. She confided, "To be honest, I don't think I even knew about STEM policy. I feel like I'm not very political. But within my school, I was big time promoting STEM." Anna recognized the importance of being knowledgeable about funding as a helpful aspect from her participation in the STA program. She mentioned, "I learned in our training about where funds come from and what funds are for and how they get distributed and 
who to talk to." Thus, enactive master experiences helped to ignite latent desires in promoting K-12 STEM education issues among STAs.

\section{Vicarious Experiences}

After enactive master experiences, vicarious experiences was the second most frequent construct of self-efficacy $(N=29,18 \%)$. As STAs referenced successful models (e.g., mentors and other STA colleagues), they observed successful STEM education advocacy. Mark, who had the least amount of teaching experience in the group, alluded to the fact that being in the program and observing how his STA colleagues advocated for STEM education was a significant motivator for him to do the same. He divulged in his interview:

I think I was in the phase of my career where I didn't necessarily see myself as that advanced STEM teacher yet, which I kind of had to work on. So, definitely being a STEM Teacher Ambassador has built on my confidence, especially through the networking and through learning from the others.

Jane elaborated upon the importance of mentorship within advocacy, expressing that younger, novice teachers should be encouraged to become advocates. She stated:

I think we need to use the seasoned teachers as mentors and involve the younger teachers in training [...] And I think they can teach us, you know, the little tricks of the trade with that, I think, what they, what their thoughts are, in issues are important.

By mentoring novice STEM teachers in advocacy, Jane argued that there is a potential for reciprocal learning as seasoned STEM teacher advocates may be well informed and gain a holistic perspective on often overlooked issues that novice STEM teachers face.

STAs were also cognizant of the work that other STAs were doing for STEM education advocacy. Mary stated in the focus group:

If Dave can get out there and demand that his state has better STEM standards, then I can champion for my teachers to have more time. If he could take on the whole state, I can take on a few people.

This type of positive influence, driven by vicarious learning experience, was particularly present in many of the re/tweets posted by STAs. Mark tweeted "It is an honor to be included in this group of amazing educators! Meeting all of you has been inspirational!! I truly am blessed to know you and have the opportunity to promote STEM education with you!!" Tweet data held numerous references and tags to what their colleagues were doing in regard to K-12 STEM education advocacy.

A few references were made in regard to making comparisons between STAs' advocate identities to other teachers (e.g., previous STAs) who were successful in their advocacy practices. For instance, Paul referenced being able to pursue an advocate identity after hearing about the first cohort's advocacy experiences. He stated, 'I don't think that at any other point ... before being a STEM advocate, I would have 
considered what I was doing advocacy." Meanwhile, Ben pointed to how seeing tweets from other STAs motivated him to pursue more advocacy activity, explaining, "My own personal network was added to through the creative network of the STEM ambassadors. Seeing the tweets that they are doing is making me more aware. I think that has influenced me and that I'm growing and learning."

\section{Verbal Persuasion}

Evidence of verbal persuasion was found throughout STAs' careers, influencing them to advocate for STEM education $(N=20$, from 157 total codes). STAs indicated that early on in their careers as novice teachers, colleagues and administrators alike encouraged them to pursue leadership opportunities for STEM education. Mark, in his individual interview, mentioned:

I had a colleague and administrator who kind of was like, 'Hey, why don't you try, you know, doing this with your class' or wanting to participate in this PD. This encouragement eventually motivated me to go to D.C. and get trained to speak on behalf of STEM or fight for STEM.

As another example, Mary spoke about how she was encouraged by one of the STAs in the previous cohort, stating:

Sue told me about it and what they did in their work. I was interested in learning how to better lead and have a better voice. They told me that that would be a good avenue for me, and that would be a good fit. And so, I applied, and I was selected.

On the other hand, some STAs also articulated experiences in being verbally discouraged to implement STEM pedagogical practices due to its incongruency with the current curriculum, as Ben articulated in his individual interview:

I've always been kind of a STEM person; I was hired as a science teacher in my district that I'm in now. I was literally told, like, I cannot do hands-on science teacher, being told, no, you can only teach science every other day. I got poor evaluations, and you have to teach, you know, nonfiction in science, and [the students] have to read in science and not, you know, do hands-on. And that the hands-on wasn't on the test.

\section{Emotional Arousal}

There were only a few references in regard to positive emotional arousal and how those feelings improved advocacy self-efficacy $(N=22,13 \%)$. Initially, some STAs mentioned having anxiety when starting to advocate for K-12 STEM education, yet professional maturity gave STAs the confidence to subdue these anxieties. Beth shared during her interview, "I think leadership is really being able to take on any kind of leadership role related to STEM teaching is really a way to figure out or to feel like you really had something to contribute." 
Meanwhile, another STA, Anne, described having a difficult time keeping up with the advocacy work due to health issues that she and her family were experiencing. She stated:

And there was just too much going on with my mom being sick and my daughter and her baby. It was just one thing after another. I also had some health issues. I felt so bad. I feel like okay, I let these people down. But I was like, you know, at this point in my life, I was like, I have to let something go.

While it was important for Anne to keep up with her professional duties, taking care of personal health matters was a priority.

\section{Discussion}

The purpose of this research was to explore the development of STAs' (a proxy for K-12 STEM teacher leaders) individual self-efficacy in STEM education advocacy via influence of the four sources of self-efficacy. Based on data collected from the STA group in regard to their advocacy experiences before, during, and after participation in the STA program, self-efficacy was found to be situative and extended to contexts of advocacy. Findings from this study suggest that self-efficacy theory, which has been used to model how teachers develop instructional leadership, was also able to model teachers' development in policy-based leadership. There is evidence to suggest that first-hand STEM education advocacy practice, observances of advocate role models, external and internal encouragement to advocate, and the ability to navigate through challenges influenced this type of advocacy self-efficacy. While enactive master experiences were the most influential source, the other sources of vicarious experiences, verbal persuasion, and emotional arousal all played smaller yet still significant roles.

Evidence in the present study suggests that training (e.g., enactive master experiences) through sustained (duration) and specific (advocacy) PD, particularly in providing policy knowledge and promoting advocacy pursuits, aided in establishing foundational self-efficacy in STEM education advocacy. This finding confirms Bandura's (1977, 1997) assertion that enactive mastery experiences were the most influential source of self-efficacy. While participants articulated that advocacy is a natural role carried out by the typical teacher in an instructional leadership role, increased participation in STEM education advocacy helped to sustain them in their goal of present and future advocacy activities. Concurrent research by Catapano (2006) found great improvements among pre-service teachers' confidence to serve urban students when given advocacy training. This finding is also supported in the literature describing how teachers who participate in the policy-making process are more inclined to provide substantial input that would help improve education outcomes (Jones et al., 2017). Furthermore, being instructional leaders (i.e., having gone through both positive and negative experiences which shaped their expertise and subsequent leadership) influenced STAs' decisions to become STEM education advocates. Wenner and Campbell (2018) have classified this type of leadership as thick leadership, which was evidenced in the present study as classroom and instructional expertise combined with passion and 
desire, facilitated leadership in novel domains like equity and social justice in (i.e., advocacy for) STEM education. Further research is needed to explore this transition, and generative experiences therein, as teachers advance from instructional leadership to policy leadership (Hite \& Milbourne, 2018; Velasco, 2020).

Though not as influential as enactive mastery experiences, the other three sources of self-efficacy nevertheless contributed to STAs' advocacy self-efficacy. For vicarious experiences, STAs learned from others by actively observing colleagues who are currently advocating for STEM education. We found that STAs are simultaneously navigating their identities as STEM teacher advocates and assessing their abilities vicariously through successful role models or other colleagues. This suggests a need for additional research and support for networking among teacher leaders to nurture and sustain nascent skills in advocacy (Berry, Norton, \& Byrd, 2007), especially online (Riel \& Becker, 2008). We also found evidence that an enhancement of STEM teacher leader advocacy self-efficacy was manifested through verbal persuasion, mainly in the form of external influence and particularly through STEM networks or partnerships. Because of their extant status as PAEMST awardees, most STAs indicated that they were specifically recruited to participate in state-led STEM initiatives. Participation in partnerships and networks improves teachers' access to information and advocacy efforts (Lambert, 2003). For self-efficacy in advocacy, the present study suggests the importance of and calls for more salient avenues for STAs and other STEM teacher leaders to share in their advocacy training experiences and activities, which may potentially increase emerging advocates' participation in this type of STEM teacher leadership. Finally, emotional arousal was the self-efficacy construct with the least number of utterances, which coincides with self-efficacy modeling that indicates that utterances do not directly mediate one's selfefficacy beliefs, influencing cognition instead (Bandura, 1997). It may be that, currently, STAs implicitly understand the current state of teacher voice within the American education system, considering the consequences of advocating publicly for reform (Athanases \& de Oliveira, 2007). In other words, STAs were more inclined to advocate because they felt that there were challenges, obstacles, and a lack in opportunities in providing input to education policy. The STAs came to understand that changes to policy are not possible without first speaking up. Teacher voice is critical in the policy-making process (Pennington, 2013), making it clear that STEM teachers are key players in providing ethical activism in the classroom (Bradley-Levine, 2018) and needed as bellwethers for STEM education reforms (NRC, 2014). Not only do these STEM teachers' voices provide significant input for policy due to their knowledge and expertise in STEM content and pedagogy, they help to bridge the process between creation and implementation of education policy (Jessop \& Penny, 1998).

Overall, findings of the present study suggest that participation in sustained and specific advocacy PD established the foundation of mastery experiences necessary to influence and foster STA self-efficacy. From these generative enactive master experiences, vicarious experiences, verbal persuasion, and emotional arousal played smaller yet important roles. Furthermore, self-efficacy theoretical concepts were affirmed when STAs who felt successful in advocacy indicated that they were more inclined to continue in the work that they were doing, even faced with 
trials and obstacles. STEM teacher leaders who advocated were also highly encouraged and motivated to continue in their current work by observing other highly capable individuals who did the same (i.e., social persuasions and vicarious experiences), evidencing a synergetic effect which has been seen in other studies (Gibbs, 2007), and evidenced as important for the development of women's selfefficacy (Zeldin, Britner, \& Pajares, 2008). When STEM teacher leaders see other leaders (in similar positions) engage in advocacy, they feel more empowered to participate in advocacy; this occurs when the advocacy activities involve policies that affect them or their students directly or indirectly (Carr, 2003).

\section{Limitations and Conclusion}

There were certain limitations associated with the present study. Data collected from participants was for a specific professional development program, which was for policy training and not explicitly for teacher leadership development in policy advocacy. While the purpose of the present study was not to evaluate the outcomes of the program, experiences presented and shared here may not be consistent with experiences and observations made by others who advocate for STEM education or other advocacy training programs related to STEM education. Another limitation was that not all participating STAs provided the requested documents used as data sources for analysis. For instance, only three policy letters and three articles were submitted to researchers and only six of the 11 STAs were able to participate in the focus group study. Furthermore, only a handful of STA participants utilized Twitter (a data source) on a regular basis. We provided Table 2 for transparency in the data collection process, although we recognize that the higher amount of data sourced from the individual interviews may have over-contributed to the frequency of utterances presented in the results. While these specific circumstances were beyond the control of the participants and the researchers, having a larger amount of data may have revealed more nuanced findings among the individuals in the study. Moreover, data saturation ensured description of self-efficacy and outcomes among the larger group of STAs.

The present study uniquely contributes to the literature on self-efficacy, evidencing how Bandura's $(1977,1997)$ theory was able to model the novel context of STEM teacher self-efficacy in advocacy. From this research, we recommend that school districts recruit STEM teachers with instructional expertise, leadership, and who are interested in gaining leadership in advocacy. Recruited STEM teachers should also be provided or guided toward PD that provides the foundational knowledge and skills of the policy-making process. If advocacy is a domain of robust teacher leadership for the success of STEM schools and students (TLEC, 2012), we argue that it is critical for STEM teacher leaders to engage in PD to not only ascertain their knowledge of policy, but also to inform them of current STEM education policy and afford them the skills on how to effectively advocate. We contend that this development may be accomplished by leveraging aspects of self-efficacy so as to inform programmatic experiences in advocacy practices that transform instructional leaders into policy leaders and active STEM education advocates. 


\section{Appendix 1. Individual Semi-structured Interview Protocol}

Please describe the extent to which you have advocated for STEM education prior to and since your selection as a STEM teacher ambassador.

\section{Possible Follow-up Questions}

Background:

- How did you hear about the STEM Teacher Ambassador program?

- Probe: Was it luck, a colleague, having participated in some other teacher leadership program?

- Why (or when) did you decide to apply for the STEM teacher ambassador program?

- How has being a STEM teacher ambassador changed your ideas of what it means to be a STEM teacher?

- What was your biggest challenge in your professional learning in the STEM teacher ambassador program?

- What was your biggest takeaway(s) from your experiences in the STEM teacher ambassador program?

Outcome 1 - shifts in individual teacher identity:

- How has your teaching changed since your participation in the STEM teacher ambassador program?

- Probe: Do you feel more competent in teaching STEM?

More knowledgeable of issues in STEM Education?

More engaged in the STEM education community?

Outcome 2 - advocacy activity:

- Since your participation, how have you come to understand what advocating for STEM education entails?

- What were you doing for STEM education that you thought was advocacy before the program?

- Do you feel that your actions prior to being a STEM ambassador count as advocacy?

- What are you doing now for STEM education, regarding advocacy, after the program?

- How are your advocacy experiences similar and/or different from pre- to postprogram participation?

Outcome 3 - advocacy networks:

- How has your experience as a STEM teacher ambassador influenced your role as an advocate for STEM education in your classroom? 
- How has your experience as a STEM teacher ambassador influenced or changed your activity in advocacy for STEM education? (school, district, state, national)

- Probe: What are some shifts in the level of your STEM education advocacy?

- Example: High school to more K-12?

- Probe: What are some shifts in the scale of your STEM education advocacy?

- Example: Building to district, or district to state, state to national?

- Probe: Have you engaged in any policy discussions or actions as a result of your advocacy?

- Why or why not?

- How has working and collaborating with the current and past STEM teacher ambassadors influenced, if at all, your role in advocating for STEM education?

- Probe: Why? Or, why not?

End question:

- Is there anything else that you would like to share in terms of your experience as a STEM teacher ambassador?

\section{Appendix 2. Focus Group Interview Protocol}

Please describe your experiences in advocating for STEM education as a STEM Teacher Ambassador.

\section{Possible Follow-up Questions}

Initial feelings:

- As previous PAEMST recipients, please describe your thought process when you saw the call to apply for the STA program?

- Was there anything from the application process that stood out to you?

- Do you remember any specific items from the application?

- Based on the call description, did you feel qualified for this position?

- What went through your mind when you were notified that you were selected to be a STA?

Training:

- Could you please further elaborate on your experiences during the week-long training session that occurred in D.C.?

- Was there anything they presented that you already knew about?

- Did you know what to expect from the training before you arrived in D.C.?

- Which part of the training, if any, did you feel needed more time to be harped on? 
- Did you know of the other STAs or any of their work before you convened in D.C. for training?

Post-training:

- During the individual interviews, many of you mentioned that the biggest takeaway you received from this entire experience was networking with your cohort. Could you elaborate a little more in that regard?

- Have you collaborated with others in your/the other cohort? How?

- How has collaborating with other STAs in advocacy differed from your experiences in advocating individually?

- I understand that the grant for this program just ended. To what extent do you feel that a program like this would be necessary for others who may desire to be in the same position that you are in?

- Can you speak to some tangible instance on how your advocacy has made an impact on student success?

End question:

- Is there anything else that you would like to share in terms of your experiences as STEM teacher ambassadors?

Acknowledgements The authors would like to recognize the NSTA/NCTM STEM Teacher Ambassadors for their participation in this study. The authors would also like to recognize Dr. Lee Kenneth Jones and Feliza Mercado for their contributions in inter-coding data.

Author Contribution Richard Velasco conducted the data collection, led in the data analysis interpretation, and led in the writing of the manuscript. Rebecca Hite conceptualized the study and oversaw the data collection and analysis. Rebecca Hite and Jeffrey Milbourne aided in the writing and editing of the manuscript.

\section{Declarations}

Competing Interests The authors declare no competing interests.

Open Access This article is licensed under a Creative Commons Attribution 4.0 International License, which permits use, sharing, adaptation, distribution and reproduction in any medium or format, as long as you give appropriate credit to the original author(s) and the source, provide a link to the Creative Commons licence, and indicate if changes were made. The images or other third party material in this article are included in the article's Creative Commons licence, unless indicated otherwise in a credit line to the material. If material is not included in the article's Creative Commons licence and your intended use is not permitted by statutory regulation or exceeds the permitted use, you will need to obtain permission directly from the copyright holder. To view a copy of this licence, visit http://creativecommons.org/licenses/by/4.0/. 


\section{References}

Alemdar, M., Cappelli, C. J., Criswell, B. A., \& Rushton, G. T. (2018). Evaluation of a Noyce program: Development of teacher leaders in STEM education. Evaluation and Program Planning, 71, 1-11.

Athanases, S. Z., \& de Oliveira, L. C. (2007). Conviction, confrontation, and risk in new teachers' advocating for equity. Teaching Education, 18(2), 123-136.

Bandura, A. (1977). Self-efficacy: Toward a unifying theory of behavioral change. Psychological Review, 84(2), 191-215.

Bandura, A. (1997). Self-efficacy: The exercise of control. Freeman.

Barcelona, K. (2014). 21st century curriculum change initiative: A focus on STEM education as an integrated approach to teaching and learning. American Journal of Educational Research, 2(10), 862-875.

Berman, P., \& McLaughlin, M. W. (1977). Federal programs supporting educational change. In Factors affecting implementation \& continuation. Report No. R-1589/7 HEW (Vol. III). Santa Monica, CA: Rand Corporation.

Berry, B., Norton, J., \& Byrd, A. (2007). Lessons from networking. Educational Leadership, 65(1), 48-52.

Bliss, K., \& Dressner, M. (2015). Examining advocacy activity and self-efficacy among self-efficacy educators. American Journal of Health Studies, 30(4), 172-129.

Blömeke, S., \& Klein, P. (2013). When is a school environment perceived as supportive by beginning mathematics teachers? Effects of leadership, trust, autonomy and appraisal on teaching quality. International Journal of Science and Mathematics Education, 11(4), 1029-1048.

Bonner, A., \& Tolhurst, G. (2002). Insider-outsider perspectives of participant observation. Nurse Researcher, 9(4), 7-19.

Bowen, G. A. (2009). Document analysis as a qualitative research method. Qualitative Research Journal, $9(2), 27-40$.

Bradley-Levine, J. (2018). Advocacy as a practice of critical teacher leadership. International Journal of Teacher Leadership, 9(1), 47-62.

Breen, L. J. (2007). The researcher 'in the middle': Negotiating the insider/outsider dichotomy. The Australian Community Psychologist, 19(1), 163-174.

Brooks, A. W., \& Schweitzer, M. E. (2011). Can nervous Nelly negotiate? How anxiety causes negotiators to make low first offers, exit early, and earn less profit. Organizational Behavior and Human Decision Processes, 115(1), 43-54.

Caprara, G. V., Barbaranelli, C., Steca, P., \& Malone, P. S. (2006). Teachers' self-efficacy beliefs as determinants of job satisfaction and students' academic achievement: A study at the school level. Journal of School Psychology, 44(6), 473-490.

Carr, E. S. (2003). Rethinking empowerment theory using a feminist lens: The importance of process. Affilia, $18,8-20$.

Carver-Thomas, D., \& Darling-Hammond, L. (2017). Teacher turnover: Why it matters and what we can do about it. Retrieved from https://healthyplacesindex.org/wp-content/uploads/2017/12/2017_learning _ policy_inst teacher_turnover.pdf

Castillo-Montoya, M. (2016). Preparing for interview research: The interview protocol refinement framework. The Qualitative Report, 21(5), 811-831.

Catapano, S. (2006). Teaching in urban schools: Mentoring pre-service teachers to apply advocacy strategies. Mentoring \& Tutoring, 14(1), 81-96.

Chung, Y., Yoo, J., Kim, S. W., Lee, H., \& Zeidler, D. L. (2016). Enhancing students' communication skills in the science classroom through socioscientific issues. International Journal of Science and Mathematics Education, 14(1), 1-27.

Cohen, J. L. (2010). Teachers in the news: A critical analysis of one US newspaper's discourse on education, 2006-2007. Discourse: Studies in the Cultural Politics of Education, 31(1), 105-119.

Criswell, B. A., Rushton, G. T., Nachtigall, D., Staggs, S., Alemdar, M., \& Cappelli, C. J. (2018). Strengthening the vision: Examining the understanding of a framework for teacher leadership development by experienced science teachers. Science Education, 102(6), 1265-1287.

Dworkin, S. L. (2012). Sample size policy for qualitative studies using in-depth interviews. Archives of Sexual Behavior, 41(6), 1319-1320.

Elrod, S., \& Kezar, A. (2017). Increasing student success in STEM: Summary of a guide to systemic institutional change. Change: The Magazine of Higher Learning, 49(4), 26-34.

Falk, K., \& Finkel, S. (2018). NSTA and NCTM Select 2018 STEM Teacher Ambassadors [News bulletin]. Retrieved from https:/www.nctm.org/News-and-Calendar/News/NCTM-News-Releases/NSTA-andNCTM-Select-2018-STEM-Teacher-Ambassadors/ 
Gen, S., \& Wright, A. C. (2013). Policy advocacy organizations: A framework linking theory and practice. Journal of Policy Practice, 12(3), 163-193.

Gibbs, S. (2007). Teachers' perceptions of efficacy: Beliefs that may support inclusion or segregation. Educational and Child Psychology, 24(3), 47-53.

Guo, C., \& Saxton, G. D. (2014). Tweeting social change: How social media are changing nonprofit advocacy. Nonprofit and Voluntary Sector Quarterly, 43(1), 57-79.

Hite, R., \& Milbourne, J. (2018). A proposed conceptual framework for K-12 STEM master teacher (STEMMaTe) development. Education Sciences, 8(4), 1-25. https://doi.org/10.3390/educsci8040218.

Hofstein, A., Carmi, M., \& Ben-Zvi, R. (2003). The development of leadership among chemistry teachers in Israel. International Journal of Science and Mathematics Education, 1(1), 39-65.

Honey, M., Pearson, G., \& Schweingruber, H. (Eds.). (2014). STEM integration in K-12 education: Status, prospects, and an agenda for research (Vol. 500). National Academies Press.

Jessop, T., \& Penny, A. (1998). A study of teacher voice and vision in the narratives of rural South African and Gambian primary school teachers. International Journal of Educational Development, 18(5), 393403.

Jones, D., Khalil, D., \& Dixon, R. D. (2017). Teacher-advocates respond to ESSA: "Support the good partsResist the bad parts". Peabody Journal of Education, 92(4), 445-465.

Kokka, K. (2018). Radical STEM teacher activism: Collaborative organizing to sustain social justice pedagogy in STEM Fields. The Journal of Educational Foundations, 31(1/2), 86-113.

Krueger, R. A., \& Casey, M. A. (2014). A practical guide for applied research (5th ed.). Sage Publications, Inc..

Kvale, S. (2006). Dominance through interviews and dialogues. Qualitative Inquiry, 12(3), 480-500.

Lambert, L. (2003). Leadership redefined: An evocative context for teacher leadership. School Leadership \& Management, 23(4), 421-430.

Leithwood, K., \& Jantzi, D. (2008). Linking leadership to student learning: The contributions of leader efficacy. Educational Administration Quarterly, 44(4), 496-528.

Lincoln, Y. S., \& Guba, E. G. (1985). Naturalistic inquiry. Sage Publications.

Lunenburg, F. C. (2011). Self-efficacy in the workplace: Implications for motivation and performance. International Journal of Management, Business, and Administration, 14(1), 1-6.

McPherson, M., Budge, K., \& Lemon, N. (2015). New practices in doing academic development: Twitter as an informal learning space. International Journal for Academic Development, 20(2), 126-136.

Merrill, C., \& Daugherty, J. (2010). STEM education and leadership: A mathematics and science partnership approach. Journal of Technology Education, 21(2), 21-34.

Miles, M. B., \& Huberman, A. M. (1994). Qualitative data analysis. Sage Publications.

Morris, M., Chrispeels, J., \& Burke, P. (2003). The power of two: Linking external with internal teachers' professional development. Phi Delta Kappan, 84(10), 764-767.

Muijs, D., \& Harris, A. (2003). Teacher leadership - Improvement through empowerment? An overview of the literature. Educational Management \& Administration, 31(4), 437-448.

National Education Association. (2019). Science, technology, engineering, and math (STEM). Retrieved from http://www.nea.org/home/stem.html

National Research Council. (2014). Exploring opportunities for STEM teacher leadership: Summary of a convocation. Washington, DC: The National Academies Press. Retrieved from http:// thescienceexperience.org/Books/Exploring_Opportunities_for_STEM_Teacher_Leadership.pdf

Nguyen, T. D., \& Hunter, S. (2018). Towards an understanding of dynamics among teachers, teacher leaders, and administrators in a teacher-led school reform. Journal of Educational Change, 19(4), 539-565.

NVivo 12 [Computer software]. (2018). Retrieved from https://www.qsrinternational.com/nvivo/nvivoproducts/nvivo-12-mac

Pajares, F. (1996). Self-efficacy beliefs in academic settings. Review of Educational Research, 66(4), 543578.

Pennington, K. (2013). New organizations, new voices: The landscape of today's teachers shaping policy. Center for American Progress. Retrieved from https:/www.americanprogress.org/issues/education-k-12/ reports/2013/06/18/66800/new-organizations-new-voices/

Perera, H. N., Calkins, C., \& Part, R. (2019). Teacher self-efficacy profiles: Determinants, outcomes, and generalizability across teaching level. Contemporary Educational Psychology, 58, 186-203.

Ralph, N., Birks, M., \& Chapman, Y. (2014). Contextual positioning: Using documents as extant data in grounded theory research. SAGE Open, 4(3), 1-7.

Riel, M., \& Becker, H. J. (2008). Characteristics of teacher leaders for information and communication technology. In J. Voogt \& G. Knezek (Eds.), International handbook of information technology in primary and secondary education (pp. 397-417). Springer: Boston, MA. 
Saldaña, J. (2015). The coding manual for qualitative researchers (2nd ed.). Sage Publications.

Sunderman, G. L., Tracey, C. A., Kim, J., \& Orfield, G. (2004). Listening to teachers: Classroom realities and no child left behind. Harvard University.

Taylor, J. (2011). The intimate insider: Negotiating the ethics of friendship when doing insider research. Qualitative Research, 11(1), 3-22.

Teacher Leadership Exploratory Consortium. (2012). Teacher leader model standards. Retrieved from www. teacherleaderstandards.org

Tschannen-Moran, M., Hoy, A. W., \& Hoy, W. K. (1998). Teacher efficacy: Its meaning and measure. Review of Educational Research, 68(2), 202-248.

U.S. Department of Education (n.d.). Every student succeeds act (ESSA). Retrieved from https://www.ed.gov/ essa? src $=\mathrm{rn}$

Unluer, S. (2012). Being an insider researcher while conducting case study research. Qualitative Report, 17, $1-14$.

Vakil, S., \& Ayers, R. (2019). The racial politics of STEM education in the USA: Interrogations and explorations. Race Ethnicity and Education, 22, 449-458.

Velasco, R. C. L. (2020). Voices for STEM education: Analyzing advocacy activities of American K-12 STEM teachers [Doctoral dissertation, Texas Tech University]. Texas Tech University Libraries.

Weiss, I. R., Smith, P. S., \& O'Kelley, S. K. (2009). The Presidential award for excellence in mathematics teaching: Setting the standard. In J. Cai, G. Kaiser, B. Perry, \& N.-Y. Wong (Eds.), Effective mathematics teaching from teachers' perspectives (pp. 281-301). Brill Sense.

Wenner, J. A., \& Campbell, T. (2017). The theoretical and empirical basis of teacher leadership: A review of the literature. Review of Educational Research, 87(1), 134-171.

Wenner, J. A., \& Campbell, T. (2018). Thick and thin: Variations in teacher leader identity. International Journal of Teacher Leadership, 9(2), 5-21.

Wynne, J. (2001). Teachers as leaders in education reform. ERIC Digest. Retrieved from ERIC database. (ED462376).

Yin, R. K. (2018). Case study research and applications: Design and methods (6th ed.). Sage Publications.

York-Barr, J., \& Duke, K. (2004). What do we know about teacher leadership? Findings from two decades of scholarship. Review of Educational Research, 74(3), 255-316.

Yow, J. A., Wilkerson, A., \& Gay, C. (2020). Mathematics and science teacher leadership understanding through a teacher leadership course. International Journal of Science and Mathematics Education, 19, 839-862.

Zeldin, A. L., Britner, S. L., \& Pajares, F. (2008). A comparative study of the self-efficacy beliefs of successful men and women in mathematics, science, and technology careers. Journal of Research in Science Teaching, 45(9), 1036-1058.

\section{Affiliations}

\section{Richard Carlos L. Velasco ${ }^{1} \cdot$ Rebecca Hite $^{2}$ - Jeff Milbourne ${ }^{3}$}

1 University of Iowa, 240 S Madison St, Iowa City, IA 52242, USA

2 Texas Tech University, 3002 18th Street, Lubbock, TX 79409, USA

3 San Luis Obispo, CA 93401, USA 